\title{
Cerrahi Tedavi Uygulanan Glioblastomlu Hastalarda Prognostik Faktörler ve Peritümöral Ödemin Sağ Kalım Üzerine Etkisi
}

\author{
Prognostic Factors and Effect of Peritumoral Edema on Survival in Patients \\ with Glioblastoma underwent Resection
}

\author{
Alican TAHTA \\ Medipol Mega Üniversite Hastanesi, Beyin ve Sinir Cerrahisi Bölümü, İstanbul, Türkiye \\ ORCID ID: Alican Tahta 0000-0003-0467-7521
}

Bu makaleye yapılacak atıf: Tahta A. Cerrahi Tedavi Uygulanan Glioblastomlu Hastalarda Prognostik Faktörler ve Peritümöral Ödemin Sağ Kalım Üzerine Etkisi. Med J West Black Sea. 2021;5(2):226-231.

Sorumlu Yazar

Alican Tahta

E-posta

atahta@medipol.edu.tr
Geliș Tarihi

25.01.2021

Revizyon Tarihi

01.03.2021

Kabul Tarihi

01.03.2021
Öz

Amaç: Cerrahi rezeksiyon sonrasında radyoterapi ve eş zamanlı kemoterapi uygulanan glioblastomlu hastaların genel özellikleri, sağ kalım süreleri, buna etki eden faktörleri ve peritümöral ödemin sağ kalıma etkisi geriye doğru incelenerek sonuçlar literatürle karşılaştırılmıştır.

Gereç ve Yöntemler: Bu çalışmada Mayıs 2014-Kasım 2020 tarihleri arasında cerrahi rezeksiyon uygulanan ve histopatolojik tanısı WHO klasifikasyonuna göre glioblastom olan 69 hasta dahil edilmiştir. Çalışmaya 18 yaş üzerinde, takip süresi 2 aydan uzun olan ve radyoterapi ile eş zamanlı temozolomid tedavisi uygulanan hastalar dahil edilmiştir. Bilateral özellik gösteren, beyin sapı, talamus, infratentorial yerleşimli kitlesi olan hastalar ve sadece biyopsi yapılan hastalar dahil edilmemiştir.

Bulgular: Yaş $(p=0,015)$ ve rezeksiyon miktarının $(p=0,044)$ glioblastomlu hastalarda prognostik faktör olduğu ortaya konulmuştur. Tanı anındaki peritümöral beyin ödemi, cinsiyet, kitlenin yerleştiği taraf ve tümör boyutu prognostik faktör olarak bulunmamıştır.

Sonuç: Glioblastom tanılı hastalarda peritümöral beyin ödemi, kitlenin total olarak çıkarımasını zorlaştırmaktadır. Fakat, PBÖ'nün glioblastom tanılı hastalarda prognostik bir faktör olmadığı belirlenmiştir. Anahtar Sözcükler: Glioblastom, Cerrahi tedavi, Prognostik faktörler, Peritümöral ödem

\section{ABSTRACT}

Aim: The general characteristics, survival periods, factors affecting survival and the effect of peritumoral brain edema on survival of patients with glioblastoma treated with radiotherapy and concurrent chemotherapy after surgical resection were examined retrospectively and the results were compared with the literature.

Material and Methods: In this study, 69 patients who underwent surgical resection between May 2014 and November 2020 and whose histopathological diagnosis was glioblastoma according to the WHO classification were included. Patients over 18 years of age, with a follow-up period of more than 2 months and treated with radiotherapy simultaneously with temozolomide were included in the study. Patients with bilateral, brainstem, thalamus, infratentorial involvement and patients who only had biopsy were not included.

Results: Age $(p=0.015)$ and amount of resection $(p=0.044)$ were found to be prognostic factors in patients with glioblastoma. Peritumoral brain edema at the time of diagnosis, gender, site of the mass and tumor size were not found as prognostic factors.

Conclusion: Peritumoral edema makes total removal of the mass difficult in patients with a diagnosis of glioblastoma. However, it has been determined that peritumoral edema is not a prognostic factor.

Keywords: Glioblastoma, Surgical treatment, Prognostic factors, Peritumoral edema 


\section{Giriş}

Glioblastom erişkinlerde en sık görülen primer malign beyin tümörüdür. İnsidansı 3-4/100.000'dir (1,2). Erkeklerde daha sık görülmektedir (1). Hastalar sıklıkla 50 yaş üzerindedir. Cerrahi rezeksiyon yapılan hastalarda ortalama yaşam süresi 12-16 aydır (3). Cerrahi rezeksiyon yapılmayan hastalarda ortalama yaşam süresi 4 ay-1 yıldır $(4,5)$. Hastaların sadece \%2-3'ü 5 yıldan fazla yaşayabilmektedir $(6,7)$.

Glioblastomda standart tedavi cerrahi rezeksiyondur. Çeşitli klinik, radyolojik, moleküler ve histolojik özelliklerin glioblastomlu hastalarda prognozu etkilediği saptanmıştır. Bunlardan en önemlileri yaş, karnofsky performans skoru, tümörün çıkarılma miktarı (total/subtotal), postoperatif kemoterapi ve radyoterapi ve kortikosteroid kullanımıdır (812). EGFR, MGMT ve IDH-1 gibi moleküllerin de prognoza etki ettiği gösterilmiştir (13-15).

Peritümoral beyin ödemi (PBÖ) glioblastomlu hastalarda sıklıkla saptanmaktadır. Bu ödemin vazojenik olduğu düşünülmekle birlikte tümöre bağlı çeşitli faktörlere de bağlı olduğu düşünülmektedir $(16,17)$. PBÖ nörolojik bulgu ve semptomlara neden olmakta ve hastalığın tedavisini güçleştirmektedir. Tanı anında saptanan PBÖ'nün prognoza olan etkisi hakkında literatürde farklı çalışmalar bulunmakla birlikte sonuçlar çelişkilidir. PBÖ'nün negatif prognostik faktör olduğu gösterilmiştir $(16,18,19)$. Aynı zamanda prognoza etki etmediğini gösteren çalışmalar da bulunmaktadır (10).

Bu çalışmada amaç, İstanbul Medipol Üniversitesi Beyin ve Sinir Cerrahisi Kliniği'nde cerrahi rezeksiyon sonrasında radyoterapi ve eş zamanlı kemoterapi uygulanan glioblastomlu hastaların genel özelliklerini, sağ kalım sürelerini, bunlara etki eden faktörleri ve PBÖ’nün sağ kalıma etkisini geriye doğru inceleyerek sonuçları literatürle kıyaslamaktır.

\section{GEREÇ ve YÖNTEMLER}

Çalışmaya başlamadan önce etik kurul onayı (İstanbul Medipol Üniversitesi Yerel Etik Kurulu, Karar No: 948) alınmış ve Helsinki beyannamesinde yer alan etik kurallara uyulmuştur. Bu tek merkezli, retrospektif çalışmaya Mayıs 2014-Kasım 2020 tarihleri arasında cerrahi rezeksiyon uygulanan ve histopatolojik tanısı WHO klasifikasyonuna göre glioblastom olan 69 hasta dahil edilmiştir. Çalışmaya 18 yaş üzerinde, takip süresi 2 aydan uzun olan ve radyoterapi ile eş zamanlı temozolomid tedavisi uygulanan hastalar dahil edilmiştir. Bilateral özellik gösteren, beyin sapı, talamus, infratentorial yerleşimli kitlesi olan hastalar, sadece biyopsi yapılan hastalar ve preoperatif MRG öncesinde steroid kullanım öyküsü olan hastalar çalışmaya dahil edilmemiştir. Çalışmada, cerrahi rezeksiyona elverişli, supratentorial yerleşim gösteren, tek lezyonu olan erişkin hastalardaki prognostik faktörlerin incelenmesi amaçlanmıştır.
Hastaların ameliyat öncesi ve ameliyat sonrası 24 saat içerisinde erken dönemde yapılan beyin MRG'leri İstanbul Medipol Üniversitesi Radyoloji Anabilim Dalı'nda bulunan 1,5T veya 3T MRG cihazları ile elde edildi. PBÖ, T2 ağırlıklı incelemelerde (aksiyel ve koronal) kitlenin etrafındaki ödemin kitleye olan en uzak mesafesi ölçülerek belirlendi. $1 \mathrm{~cm}$ 'den daha fazla ödem majör, daha az ödem ise minör ödem olarak değerlendirildi. Tümör boyutu T1 ağırlıklı, kontrastı incelemelerde (aksiyel, koronal, sagital) kitlenin en büyük olduğu kesitteki boyutu hesaplanarak ölçüldü. Hastalar tümör boyutu $4 \mathrm{~cm}$ üzerindekiler ve $4 \mathrm{~cm}$ altındakiler olmak üzere iki gruba ayrıldı. Ölçümler iki farklı nöroradyolog tarafından yapılmıştır, bu ölçümler arasında istatistiksel olarak anlamlı fark saptanmamıştır.

Hastaların gözlem süreleri yaşayan olgular için hastanın ameliyat edildiği tarihten son kontrol tarihine kadar geçen süre, ölen olgular için ise ameliyat edildiği tarihten ölüm tarihine kadar geçen süre olarak hesaplandı.

\section{İstatistiksel Analiz}

Değişkenlere ait sağ kalım eğrileri Kaplan-Meier yöntemi kullanılarak işaretlendi ve log-rank testi kullanılarak karşılaştırıldı. Chi Kare testi ve Yates düzeltmesi kategorik değişkenlere uygun şekilde uygulandı. Ölümle sonuçlanan risk faktörlerini tahmin etmek için değişkenler (yaş, cinsiyet, tümör boyutu, kitlenin sağ veya sol yerleşimli olması, rezeksiyon miktarı ve peritümöral ödem miktarı) tek değişkenli Cox regresyon analizleri kullanılarak değerlendirildi. Veri analizi TURCOSA Cloud (Turcosa Ltd Co, www.turcosa.com.tr) istatistik yazılımında yapıldı. Anlamlılık düzeyi $p<0,05$ olarak kabul edildi.

\section{BULGULAR}

Çalışmamıza dahil edilen 69 hastanın genel ortanca sağ kaIım süresi 13 aydı $(\% 95 \mathrm{Cl}(8,97-17,02)$ (Şekil 1). Hastaların 46 'sı $(\% 66,7)$ erkek, 23'ü $(\% 33,3)$ kadındı (Tablo 1). Erkek-

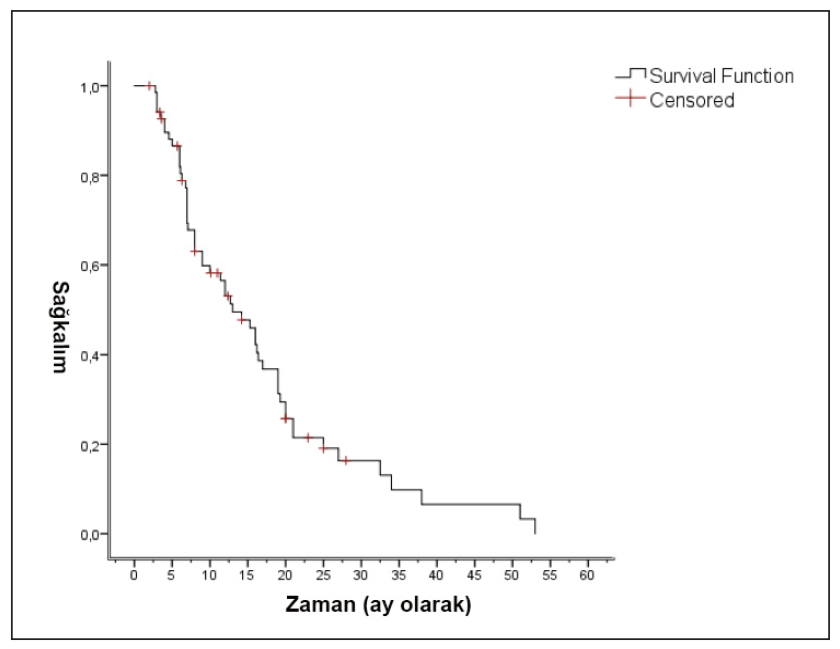

Şekil 1: Genel sağ kalıma ait Kaplan-Meier eğrisi 
lerde ortanca sağ kalım süresi 16,20 ay, kadınlarda 8 aydı $(p=0,116)$ (Tablo 2) (Şekil 2). Ortanca yaş 60'tı (20-76 yıl). Hastaların \%40,6'sı 55 yaş altındaydı. 55 yaş altında olan hastaların ortanca sağ kalım süresi 16,40 ay, 55 yaş üzerindeki hastaların ortanca sağ kalım süresi 11,40 aydı $(p=0,015)$ (Şekil 3). Regresyon analizlerinde en anlamlı risk faktörü yaş değişkeni olarak bulundu $(p=0,019)$ (Tablo 3$)$. Ortanca tümör boyutu 4 cm'ydi $(1,4-8 \mathrm{~cm})$. Hastaların $\% 56,5$ 'inde sap-

Tablo 1: Tanımlayıcı istatistikler

\begin{tabular}{|c|c|c|}
\hline Kategorik Değişkenler & Gruplar & n (\%) \\
\hline \multirow{2}{*}{ Yaş } & $\leq 55$ yıl & $28(40,6)$ \\
\hline & $>55$ yıl & $41(59,4)$ \\
\hline \multirow{2}{*}{ Cinsiyet } & Erkek & $46(66,7)$ \\
\hline & Kadın & $23(33,3)$ \\
\hline \multirow{2}{*}{ Tümör Boyutu } & $\leq 4 \mathrm{~cm}$ & $39(56,5)$ \\
\hline & $>4 \mathrm{~cm}$ & $30(43,5)$ \\
\hline \multirow{2}{*}{ Taraf } & Sağ & $27(39,1)$ \\
\hline & Sol & $42(60,9)$ \\
\hline \multirow{5}{*}{ Yerleşim yeri } & Frontal & $20(29,0)$ \\
\hline & Temporal & $22(27,5)$ \\
\hline & Parietal & $19(27,5)$ \\
\hline & Oksipital & $3(4,3)$ \\
\hline & Multifokal & $5(7,2)$ \\
\hline \multirow{2}{*}{ Rezeksiyon } & Total & $33(47,8)$ \\
\hline & Subtotal & $36(52,2)$ \\
\hline \multirow{4}{*}{ Peritümoral ödem } & $\leq 1 \mathrm{~cm}$ (Minör) & $18(26,1)$ \\
\hline & $>1 \mathrm{~cm}$ (Majör) & $51(73,9)$ \\
\hline & Yaşayan & $15(21,7)$ \\
\hline & Ölen & $54(78,3)$ \\
\hline Sürekli Değişkenler & Medyan & $\min -\max$ \\
\hline Yaş (yıl) & 60.0 & $20.0-76.0$ \\
\hline Tümör Boyutu (mm) & 40.0 & $14.0-80.0$ \\
\hline Peritümoral ödem (mm) & 17.0 & $0.0-45.0$ \\
\hline Yaşam süresi (ay) & 11.0 & $2.0-53.0$ \\
\hline
\end{tabular}

Tablo 2: Kaplan-Meier sağ kalım analizi

\begin{tabular}{|c|c|c|c|}
\hline Faktör & $\begin{array}{c}\text { Tahmin } \\
\text { Edici Faktör }\end{array}$ & Median Sağ kalım (ay) & $\begin{array}{c}\mathbf{P} \\
\text { değeri }\end{array}$ \\
\hline \multirow{2}{*}{ Yaş } & $\leq 55$ yıl & $16.40(7.62-25.18)$ & \multirow{2}{*}{0,015} \\
\hline & $\geq 55$ yıl & $11.40(5.60-17.20)$ & \\
\hline \multirow{2}{*}{ Cinsiyet } & Erkek & $16.20(11.67-20.73)$ & \multirow{2}{*}{0,116} \\
\hline & Kadın & $8.00(4.70-11.29)$ & \\
\hline \multirow{2}{*}{$\begin{array}{l}\text { Tümör } \\
\text { Boyutu }\end{array}$} & $\leq 4 \mathrm{~cm}$ & $16.40(10.84-21.96)$ & \multirow{2}{*}{0,502} \\
\hline & $>4 \mathrm{~cm}$ & $9.00(5.87-12.13)$ & \\
\hline \multirow{2}{*}{ Taraf } & Sol & $13.00(7.92-18.08)$ & \multirow{2}{*}{0,596} \\
\hline & Sağ & $4.85(4.69-23.71)$ & \\
\hline \multirow{2}{*}{ Rezeksiyon } & Total & $19.00(15.71-22.29)$ & \multirow{2}{*}{0,044} \\
\hline & Subtotal & $10.00(6.02-13.98)$ & \\
\hline \multirow{2}{*}{$\begin{array}{l}\text { Peritümoral } \\
\text { ödem }\end{array}$} & $\leq 1 \mathrm{~cm}$ & $9.00(0.00-18.22)$ & \multirow{2}{*}{0,422} \\
\hline & $>1 \mathrm{~cm}$ & $13.00(8.81-17.19)$ & \\
\hline
\end{tabular}

tanan tümör boyutu $4 \mathrm{~cm}$ altındayken \%43,5'inde $4 \mathrm{~cm}$ 'den büyüktü. Tümör boyutu $4 \mathrm{~cm}$ üzerinde olan hastalarda ortanca sağ kalım süresi 13 ay, $4 \mathrm{~cm}$ altındaki hastalarda ise 16,40 aydı $(p=0,502)$. Tanı anındaki ortanca PBÖ boyutu 1,7 cm'ydi $(0-4,5 \mathrm{~cm})$. Minör ödemi $(\leq 1 \mathrm{~cm})$ bulunan hastaların ortanca sağ kalım süresi 9 ay, majör ödemi bulunan hastalarınki ise 13 aydı $(p=0,422)$. Minör ödem ve majör ödem grupları arasında yaş, cinsiyet, tümör boyutu, yerleşim tarafı ve rezeksiyon miktarı açısından anlamlı fark saptanmadı (Tablo 4). Hastaların \%39,1'inde kitle sağda yerleşim göstermekte, $\% 60,9$ 'unda ise solda yerleşim göstermekteydi. Kitlesi sol-

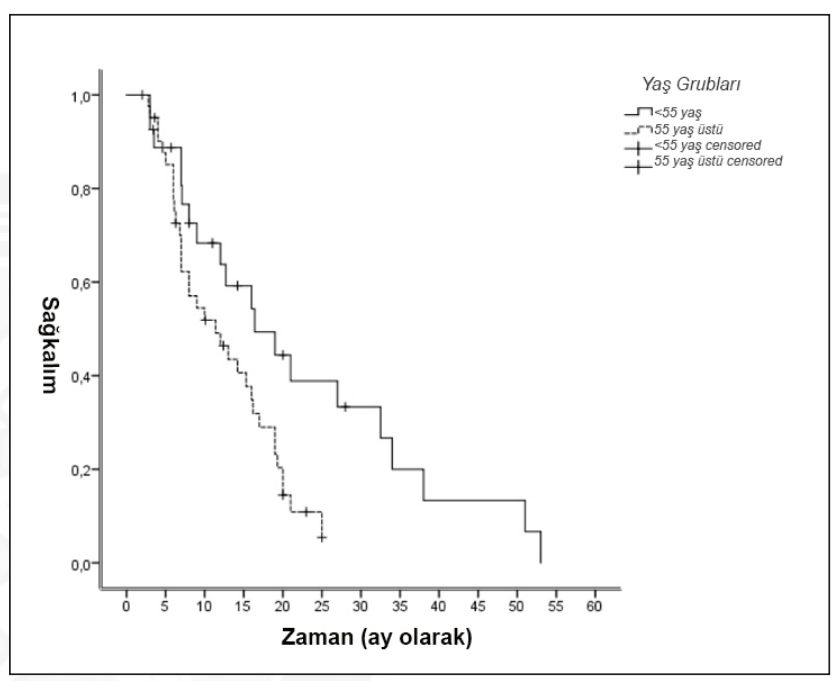

Şekil 2: Yaşa göre genel sağ kalıma ait Kaplan-Meier eğrisi

Tablo 3: Genel sağkalımın tek değişkenli Cox regresyon analizi

\begin{tabular}{|c|c|c|c|}
\hline $\begin{array}{l}\text { Kategorik } \\
\text { Değişkenler }\end{array}$ & Gruplar & $\begin{array}{c}\text { Univariate } \\
\text { HR 95\% Cl } \\
\text { (Lower-Upper) }\end{array}$ & $\mathbf{p}$ \\
\hline Yaş & $\begin{array}{l}\leq 55 \text { yıl } \\
>55 \text { yıl }\end{array}$ & $\begin{array}{c}\text { Referans } \\
2.13(1.13-3.99) \\
\end{array}$ & 0,019 \\
\hline Cinsiyet & $\begin{array}{l}\text { Erkek } \\
\text { Kadın }\end{array}$ & $\begin{array}{c}\text { Referans } \\
1.58(0.88-2.82)\end{array}$ & 0,125 \\
\hline Tümör Boyutu & $\begin{array}{l}\leq 4 \mathrm{~cm} \\
>4 \mathrm{~cm}\end{array}$ & $\begin{array}{c}\text { Referans } \\
1.21(0.69-2.13)\end{array}$ & 0,509 \\
\hline Taraf & $\begin{array}{l}\text { Sağ } \\
\text { Sol }\end{array}$ & $\begin{array}{c}\text { Referans } \\
1.16(0.66-2.04)\end{array}$ & 0,602 \\
\hline Rezeksiyon & $\begin{array}{c}\text { Total } \\
\text { Subtotal }\end{array}$ & $\begin{array}{c}\text { Referans } \\
1.76(1.00-3.08)\end{array}$ & 0,051 \\
\hline Peritümoral ödem & $\begin{array}{l}\leq 1 \mathrm{~cm} \\
>1 \mathrm{~cm}\end{array}$ & $\begin{array}{c}\text { Referans } \\
0.78(0.43-1.44)\end{array}$ & 0,430 \\
\hline \multicolumn{4}{|l|}{ Sürekli Değişkenler } \\
\hline Yaş (yıl) & & $1.039(1.01-1.07)$ & 0,009 \\
\hline Tümör Boyutu (mm) & & $1.00(0.99-1.03)$ & 0,580 \\
\hline $\begin{array}{l}\text { Peritümoral ödem } \\
(\mathrm{mm})\end{array}$ & & $0.986(0.96-1.02)$ & 0,334 \\
\hline
\end{tabular}

CI: Güven aralığı, HR: Hazard Ratio (Tehlike oranı) 


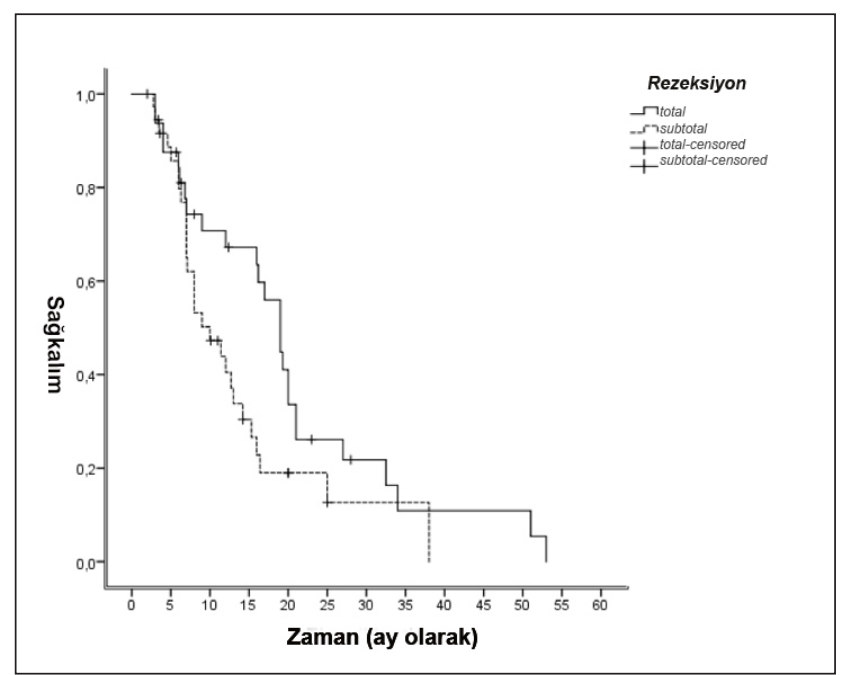

Şekil 3: Rezeksiyon miktarına göre genel sağ kalıma ait Kaplan-Meier eğrisi.

Tablo 4: Ödem grubu ile ilgi faktörlerin arasındaki ilişki

\begin{tabular}{|c|c|c|c|c|}
\hline \multirow[b]{2}{*}{ Değişkenler } & \multirow[b]{2}{*}{ Gruplar } & \multicolumn{2}{|c|}{ Ödem grubu } & \multirow[b]{2}{*}{$\underset{\text { değeri }}{p}$} \\
\hline & & $\begin{array}{c}\text { Minör ödem } \\
(\leq 1 \mathrm{~cm}) \\
\mathrm{n}(\%)\end{array}$ & $\begin{array}{c}\text { Majör ödem } \\
\text { (>1 cm) } \\
\text { n (\%) }\end{array}$ & \\
\hline Yaş & $\begin{array}{l}\leq 55 \mathrm{yll} \\
>55 \mathrm{yll}\end{array}$ & $\begin{array}{c}8(44,4) \\
10(55,6)\end{array}$ & $\begin{array}{l}20(39,2) \\
31(59,4)\end{array}$ & 0,913 \\
\hline Cinsiyet & $\begin{array}{l}\text { Erkek } \\
\text { Kadın }\end{array}$ & $\begin{array}{c}13(72,2) \\
5(27,8)\end{array}$ & $\begin{array}{l}33(64,7) \\
18(35,3)\end{array}$ & 0,771 \\
\hline $\begin{array}{l}\text { Tümör } \\
\text { Boyutu }\end{array}$ & $\begin{array}{l}\leq 4 \mathrm{~cm} \\
>4 \mathrm{~cm}\end{array}$ & $\begin{array}{c}8(44,4) \\
10(55,6)\end{array}$ & $\begin{array}{l}31(60,8) \\
20(39,2)\end{array}$ & 0,355 \\
\hline Taraf & $\begin{array}{l}\text { Sağ } \\
\text { Sol }\end{array}$ & $\begin{array}{l}8(44,4) \\
10(55,6)\end{array}$ & $\begin{array}{l}19(37,3) \\
32(62,7)\end{array}$ & 0,798 \\
\hline Rezeksiyon & $\begin{array}{c}\text { Total } \\
\text { Subtotal }\end{array}$ & $\begin{array}{c}10(55,6) \\
8(44,4)\end{array}$ & $\begin{array}{l}23(45,1) \\
28(54,9)\end{array}$ & 0,625 \\
\hline
\end{tabular}

da yerleşimli hastaların ortanca sağ kalım süresi 13 ay, sağ yerleşimlilerde ise 4,85 aydı $(p=0,596) .22(\% 31,9)$ hastada kitle temporal yerleşimliyken 20 (\%29) hastada frontal, $19(\% 27,6)$ hastada parietal, $3(\% 4,3)$ hastada ise oksipital yerleşim göstermekteydi. $5(\% 7,2)$ hastada ise multifokal kitle bulunmaktaydı. $33(\% 47,8)$ hastada total rezeksiyon uygulanmışken 36 (\%52,2) hastada subtotal rezeksiyon uygulanmıştı. Total rezeksiyon uygulanan hastaların ortanca sağ kalım süresi subtotal uygulanan hastalara kıyasla istatistiksel olarak anlamlı şekilde daha uzundu (19 ay vs 10 ay, p=0,044). Hastaların gözlendiği süre boyunca 54 hasta ölmüş, 15 hasta ise yaşamaktaydı (Takip süresi; minimum 64 gün, maksimum 1590 gün, ortanca 340 gün).

\section{TARTIŞMA}

Glioblastom en sık görülen primer malign beyin tümörüdür. Hastalar genellikle 55-60 yaş civarındadır. Erkeklerde daha sık görülür (E/K: 1,6:1). Çoğunlukla ailesel değil sporadik olarak görülürler. Cerrahi tedavi, radyoterapi ve kemoterapiyle yoğun tedaviye rağmen hastaların neredeyse hepsi glioblastom nedeniyle kaybedilir. Glioblastomun standart tedavisi cerrahi sonrası lokal radyoterapi ve temozolomidle sistemik kemoterapi şeklindedir. Hastaların beklenen yaşam süresi 12-16 aydır $(1,4)$ Bizim çalışmamızda ortanca yaşam süresi literatürdekine benzer şekilde 13 aydı. Daha önce yapılan çalışmalarda glioblastom tanılı hastaların prognozunu; tümör boyutu, tümörün lokasyonu, tümörün yayılımı, hastanın yaşı, hastanın genel durumu, peritümoral beyin ödemi gibi faktörlerin etkilediği bulunmuştur $(20,21)$. Çalışmamızda <55 yaş ve total cerrahi rezeksiyon iyi prognostik faktörler olarak saptandı. Hastaların yaşam süresini etkileyen en belirgin faktör yaş olarak bulundu.

Lacroix ve ark.'nın 416 hastadan oluşan serisinde tümörün \%98'inden fazlasının çıkarılmasının glioblastom hastalarının yaşam sürelerini uzattığı gösterilmiştir (10). Aynı şekilde Stummer ve ark.'ı da total tümör rezeksiyonunun daha uzun sağ kalımla ilişkili olduğunu göstermişlerdir (12,22). Bizim çalışmamızda da literatürdekine benzer olarak total rezeksiyonun sağ kalım üzerine istatistiksel olarak anlamlı etkisi bulunduğu gösterilmiştir (Total: 19 ay vs subtotal: 10 ay, $p=$ 0,044). Fakat literatürde total rezeksiyon tanımı hakkında farklı görüşler bulunmaktadır. Li ve ark. MRG'de kontrast tutan lezyona ek olarak FLAIR kesitlerde tümörün etrafındaki anormal görülen bölgelerin de çıkarılmasını önermektedirler (23). Fakat bu çoğu hastada mümkün olmamakla birlikte 70 yıl önce glioblastomlarda uygulanan çok geniş rezeksiyonların (hemisferektomi) sonuçları düşünüldüğünde istenen olumlu sonuçlar yerine olumsuz sonuçlara yol açabilecektir (24). Ayrıca rezeksiyon sonrası hastada yeni bir nörolojik defisit gelişmesinin prognozu olumsuz etkilediği unutulmamalıdır (25). Bu nedenle öncelikle hastanın genel durumunu kötüleştirecek bir nörolojik defisite neden olmaktan uzak durulmalı, sonrasında kitlenin total olarak çıkarılması hedeflenmelidir.

Daha önce yapılan çalışmaların büyük çoğunluğunda ileri yaşın glioblastom prognozuna olumsuz etki ettiği gösterilmiştir (26). Gately ve ark. tarafından yapılan çalışmada ise yaş ile prognoz arasında bir ilişki bulunmamıştır (27). Bu çalışmalarda yaş için sınır değer genellikle 55, 60 ya da 65 olarak kullanılmaktadır. Zhou ve ark.'nın yakın zamanda yapmış oldukları bir çalışmada hastalar 4 farklı şekilde yaş gruplarına modellenmiş ve ileri yaşın sağ kalım üzerine olumsuz etkisi olduğu gösterilmiştir (26). Bizim çalışmamızda yaş için sınır değer 55 yıl olarak belirlendi. Hastaların \%40,5’i 55 yaşın altındaydı. Literatürdeki çalışmaların sonuçlarına benzer olarak ileri yaşın ortanca sağ kalım üzerine olumsuz etkisi olduğu gösterilmiştir ( $\leq 55$ yaş: 16,40 ay vs $>55$ yaş: 11,40 ay, $p=0,015)$. Yaş arttıkça hastaların genel performanslarının azalması ve kronik hastalıkların glioblastoma eşlik etme intimali, radyoterapi ve kemoterapi 
sonrası ortaya çıkacak komplikasyonlarla baş etmenin yaşlı hastalarda daha zor olması gibi nedenlerin bu sonuca sebep olduğu düşünülmektedir.

Tümör boyutunun glioblastomu olan hastalarda genel sağ kalım üzerine olumsuz etkisi olduğu düşünülmektedir. Daha önce yapılan çalışmalarda, tümör boyutunun genel sağ kalıma olumsuz etkisi olduğu gösterilmiştir $(28,29)$. Çalışmamızda tümör boyutu $4 \mathrm{~cm}$ üzerinde ve $4 \mathrm{~cm}$ altında olan hastalar karşılaştırıldığında genel sağ kalım açısından belirgin fark saptanmamıştır. Aynı şekilde, çalışmamızda cinsiyetin ve tümörün sağ veya sol yerleşimli olmasının da genel sağ kalım üzerine belirgin bir etkisi saptanmamıştır.

Glioblastom ile birlikte sıklıkla tümörün etrafında peritümoral beyin ödemi görülür (30). Daha önceki çalışmalarda PBÖ'nün genel sağ kalıma olumsuz etkisi olduğu gösterilmiştir $(16,18,19)$. Schoenegger ve ark. ve Pope ve ark. tarafından yapılan iki farklı çalışmada PBÖ için sınır değer $1 \mathrm{~cm}$ olarak alınmış ve majör ödemi olan hastalarda prognozun daha kötü olduğu gösterilmiştir $(16,19)$. Lacroix ve ark. tarafından glioblastom tanılı 416 hastada yapılan bir çalışmada ise PBÖ'nün prognostik faktör olmadığı gösterilmiştir (10). Hammoud ve ark. tarafından yapılan çalışmada orta dereceli PBÖ'lü hastaların geniş PBÖ'lü hastalara kıyasla daha uzun sağ kalıma sahip olduğu gösterilmiştir (18). Bizim çaIışmamızda literatürdeki daha önceki benzer çalışmaların aksine, istatistiksel olarak anlamlı olmasa da majör ödemi olan hastalar minör ödemi olan hastalara kıyasla daha uzun ortanca sağ kalıma sahipti ( 9 ay vs 13 ay, $p=0,422$ ). Majör ödemin anatomik sınırların tanınmasını ve beyin dokusunun manipülasyonunu engelleyerek cerrahi rezeksiyonu zorlaştırdığı, bu yüzden de hastaların sağ kalımının daha kısa olduğu düşünülmektedir (30). Çalışmamızda bu teoriyi destekleyecek şekilde, majör ödemi olan hastaların total rezeksiyon oranları istatistiksel olarak anlamlı olmasa da daha düşük bulunmuştur (\%45,1 vs \%55,6, p=0,625). Fakat bu durumun sağ kalıma olumsuz etkisi olduğu belirlenmemiştir.

Çalışmamızda yaşın ve cerrahi rezeksiyon miktarının sağ kalım üzerinde etkili olduğu gösterilmiştir. PBÖ’nün, tümör boyutunun, cinsiyetin ise sağ kalım üzerinde etkisi saptanmamıştır. Glioblastom tanılı hastalarda PBÖ, kitlenin total olarak çıkarılmasını zorlaştırmaktadır. Fakat, PBÖ’nün glioblastom tanılı hastalarda prognostik bir faktör olmadığı belirlenmiştir.

\section{Teşekkür}

Radyolojik görüntülemelerdeki ölçümleri ve değerlendirmeleri için Prof. Dr. Ayşenur Cila ve Doç. Dr. Gülhan Ertan Akan, verilerin toplanması aşamasındaki katkıları için Dr. Berkhan Genç ve Dr. Naci Emre Akşehirli'ye emekleri için teşekkür ederiz.

\section{Yazar Katkı Beyanı}

Fikir, tasarım, veri ve literatür taraması, kaynak araştırması, makale yazımı, analiz, yorum: Alican Tahta.

\section{Çıkar Çatışması}

Çıkar çatışması bulunmamaktadır.

\section{Finansal Destek}

Araştırma kapsamında herhangi bir kurum ya da kuruluştan finansal destek sağlanmamıştır.

\section{Etik Kurul Onayı}

Araştırma için İstanbul Medipol Üniversitesi Etik Kurulu'ndan 24.12.2020 tarih ve 948 no'lu etik kurul oluru alınmıştır. Tüm hastalardan onam alınmıştır.

\section{Hakemlik Süreci}

Kör hakemlik süreci sonrası yayınlanmaya uygun bulunmuş ve kabul edilmiştir.

\section{KAYNAKLAR}

1. Ostrom QT, Gittleman H, Truitt G, Boscia A, Kruchko C, Barnholtz-Sloan JS. CBTRUS statistical report: Primary brain and other central nervous system tumors diagnosed in the United States in 2011-2015. Neuro-oncology 2018;20(suppl_4):iv1-86.

2. Arvold ND, Reardon DA. Treatment options and outcomes for glioblastoma in the elderly patient. Clin Interv Aging 2014;9:357367.

3. Sanai N, Berger MS. Glioma extent of resection and its impact on patient outcome. Neurosurgery 2008;62(4):753-766.

4. Helseth R, Helseth E, Johannesen $T$, Langberg C, Lote K, Rønning P, Scheie D, Vik A, Meling TR. Overall survival, prognostic factors, and repeated surgery in a consecutive series of 516 patients with glioblastoma multiforme. Acta Neurol Scand 2010;122(3):159-167.

5. Ryken TC, Frankel B, Julien T, Olson JJ. Surgical management of newly diagnosed glioblastoma in adults: Role of cytoreductive surgery. J Neurooncol 2008;89(3):271-286.

6. Stupp R, Mason WP, Van Den Bent MJ, Weller M, Fisher B, Taphoorn MJ, et al. Radiotherapy plus concomitant and adjuvant temozolomide for glioblastoma. $\mathrm{N}$ Engl J Med 2005;352(10):987-996.

7. Ohgaki $\mathrm{H}$, Kleihues $\mathrm{P}$. Epidemiology and etiology of gliomas. Acta neuropathol 2005;109(1):93-108.

8. Buckner JC. Factors influencing survival in high-grade gliomas. In Elsevier; 2003.10-4.

9. Carson KA, Grossman SA, Fisher JD, Shaw EG. Prognostic factors for survival in adult patients with recurrent glioma enrolled onto the new approaches to brain tumor therapy CNS consortium phase I and II clinical trials. J Clin Oncol 2007;25(18):2601-2006. 
10. Lacroix M, Abi-Said D, Fourney DR, Gokaslan ZL, Shi W, DeMonte F, Lang FF, McCutcheon IE, Hassenbusch SJ, Holland E, Hess K, Michael C, Miller D, Sawaya R. A multivariate analysis of 416 patients with glioblastoma multiforme: Prognosis, extent of resection, and survival. J Neurosurg 2001;95(2):190-8.

11. Stark AM, Nabavi A, Mehdorn HM, Blömer U. Glioblastoma multiforme-report of 267 cases treated at a single institution. Surgical Neurology 2005;63(2):162-169.

12. Stummer W. Extent of resection and survival in glioblastoma multiforme. Neurosurgery. 2009;64(6):E1206.

13. Gorlia T, van den Bent MJ, Hegi ME, Mirimanoff RO, Weller M, Cairncross JG, Eisenhauer E, Belanger K, Brandes AA, Allgeier A, Lacombe D, Stupp R. Nomograms for predicting survival of patients with newly diagnosed glioblastoma: Prognostic factor analysis of EORTC and NCIC trial 26981-22981/CE. 3. Lancet Oncol 2008;9(1):29-38.

14. Hill C, Hunter SB, Brat DJ. Genetic markers in glioblastoma: Prognostic significance and future therapeutic implications. Adv Anat Pathol 2003;10(4):212-217.

15. Shinojima N, Tada K, Shiraishi S, Kamiryo T, Kochi M, Nakamura H, Makino K, Saya H, Hirano H, Kuratsu JI, Oka $\mathrm{K}$, Ishimaru Y, Ushio Y. Prognostic value of epidermal growth factor receptor in patients with glioblastoma multiforme. Cancer Res 2003;63(20):6962-6970.

16. Schoenegger K, Oberndorfer S, Wuschitz B, Struhal W, Hainfellner J, Prayer D, Heinzl H, Lahrmann $\mathrm{H}$, Marosi $\mathrm{C}$, Grisold W. Peritumoral edema on MRI at initial diagnosis: An independent prognostic factor for glioblastoma? Eur $\mathrm{J}$ Neurol 2009;16(7):874-878.

17. Stummer W. Mechanisms of tumor-related brain edema. Neurosurgical Focus 2007;22(5):1-7.

18. Hammoud MA, Sawaya R, Shi W, Thall PF, Leeds NE. Prognostic significance of preoperative MRI scans in glioblastoma multiforme. J Neuro-Oncology 1996;27(1):65-73.

19. Pope WB, Sayre J, Perlina A, Villablanca JP, Mischel PS Cloughesy TF. MR imaging correlates of survival in patients with high-grade gliomas. American Journal of Neuroradiology 2005;26(10):2466-2474.

20. Tortosa A, Viñolas N, Villà S, Verger E, Gil JM, Brell M, Caral L, Pujol T, Acebes JJ, Ribalta T, Ferrer I, Graus F. Prognostic implication of clinical, radiologic, and pathologic features in patients with anaplastic gliomas. Cancer 2003;97(4):10631071.
21. Xue D, Albright Jr RE. Preoperative anaplastic glioma tumor volume effects on patient survival. Journal Surgical Oncology 1999;72(4):199-205

22. Stummer W, Pichlmeier U, Meinel T, Wiestler OD, Zanella F, Reulen HJ. Fluorescence-guided surgery with 5 -aminolevulinic acid for resection of malignant glioma: A randomised controlled multicentre phase III trial. Lancet Oncol 2006;7(5):392-401.

23. Li YM, Suki D, Hess K, Sawaya R. The influence of maximum safe resection of glioblastoma on survival in 1229 patients: Can we do better than gross-total resection? J Neurosurg 2016;124(4):977-988.

24. Han SJ, Sughrue ME. The rise and fall of "biopsy and radiate": A history of surgical nihilism in glioma treatment. Neurosurg Clin N Am 2012;23(2):207-14, vii.

25. Rahman M, Abbatematteo J, De Leo EK, Kubilis PS, Vaziri S, Bova F, Sayour E, Mitchell D, Quinones-Hinojosa A. The effects of new or worsened postoperative neurological deficits on survival of patients with glioblastoma. J Neurosurg 2017;127(1):123-131.

26. Zhou X, Niu X, Mao Q, Liu Y. Clinical significance of various classification standards of age groups in predicting survival of patients with glioblastoma. Med Sci Monit 2020;26:e920627.

27. Gately L, Collins A, Murphy M, Dowling A. Age alone is not a predictor for survival in glioblastoma. Journal Neuro-Oncology 2016;129(3):479-485.

28. Mazurowski MA, Zhang J, Peters KB, Hobbs H. Computerextracted MR imaging features are associated with survival in glioblastoma patients. Journal Neuro-Oncology 2014; 120(3):483-488.

29. Gutman DA, Cooper LA, Hwang SN, Holder CA, Gao J, Aurora TD, Dunn Jr WD, Scarpace L, Mikkelsen T, Jain R, Wintermark M, Jilwan M, Raghavan P, Huang E, Clifford RJ, Mongkolwat P, Kleper V, Freymann J, Kirby J, Zinn PO, Moreno CS, Jaffe C, Colen R, Rubin DL, Saltz J, Flanders A, Brat DJ. MR imaging predictors of molecular profile and survival: multi-institutional study of the TCGA glioblastoma data set. Radiology 2013;267(2):560-569

30. Marcus HJ, Williams S, Hughes-Hallett A, Camp SJ, Nandi $D$, Thorne L. Predicting surgical outcome in patients with glioblastoma multiforme using pre-operative magnetic resonance imaging: development and preliminary validation of a grading system. Neurosurgical Review 2017;40(4):621-631. 